\title{
Analysis of financial technologies as a tool for sustainable development
}

\author{
Viktoriya Dyukova ${ }^{1,}{ }^{*}$, Elizaveta Shainskaya ${ }^{2}$, and Vladimir Syrovatsky ${ }^{1}$ \\ ${ }^{1}$ Irkutsk National Research Technical University, 664074 Irkutsk, Russia \\ ${ }^{2}$ Belarus State Economic University, 220070 Minsk, Republic of Belarus
}

\begin{abstract}
The organization of the finance area is a challenge for companies in any sector. Balancing costs and income is one of the prerequisites for those looking for better profit margins, but it requires the administration of various aspects that do not always fit into a simple financial equation. Different processes and possibilities need to be explored. As you can see, money is the main character in this section. Here you will find articles on the organization of the income and expenses of your business. Working capital (also called working capital), bank credit, cash flow management and taxes are also topics covered in our practical advice. Some recommendations related to accounting are also presented. All this to help you perfectly control the financial operations of your company. And allow you to adapt the equipment and resources so that finances are in order and can consolidate the results and achievements of the rest of your business.
\end{abstract}

\section{Introduction}

In the initial phase of a business, it is common for entrepreneurs to have to resort to a reserve of money to meet financial commitments, since the profits are not immediate. To control this process, it is essential to manage working capital (all available net resources capable of covering the company's expenses).

It is necessary to be careful, since an inadequate administration of working capital can lead the enterprise to bankruptcy. For this reason, some care is essential when managing these resources.

First, it is necessary to understand what is working capital. Basically, it is an amount of money or any resource (such as stock items, for example), which can be transformed into capital to pay the immediate bills of the company.

That is, it serves as a reserve in case the expected financial return was not received, which occurs mainly when customers buy on time. In order to manage working capital, it is necessary to pay attention to some details.

The competitiveness of an economy finds support in the efficiency with which operate their financial markets. Thus, deeper and more efficient financial markets tend to increase

\footnotetext{
${ }^{*}$ Corresponding author: minyaylova96@ mail.ru
} 
competitiveness through reduction of acquisition, processing and production of information on investment options, so that savers can use their resources from the more productive way.

Also, deeper financial markets play an important role in assigning resources within the economy (companies, sectors), in order to achieve higher productivity added to allow highly productive companies and industries to grow, while less productive ones reduce their participation in the business fabric [17].

Despite the remarkable progress of the Peruvian financial system since the decade of the nineties, mainly in terms of regulation and stability of institutions, the degree of deepening of the local market is still small, mainly in terms of domestic credit to the private sector, capitalization and negotiated amounts of the stock market and premiums insurance. This especially compared to others economies of the region and the world highlighting the inefficiencies that exist in channeling capital between savers and borrowers [1].

Consider deepening the financial system of Peru, the Pacific Alliance, the OECD (score from 1 to 100) in Fig. 1.

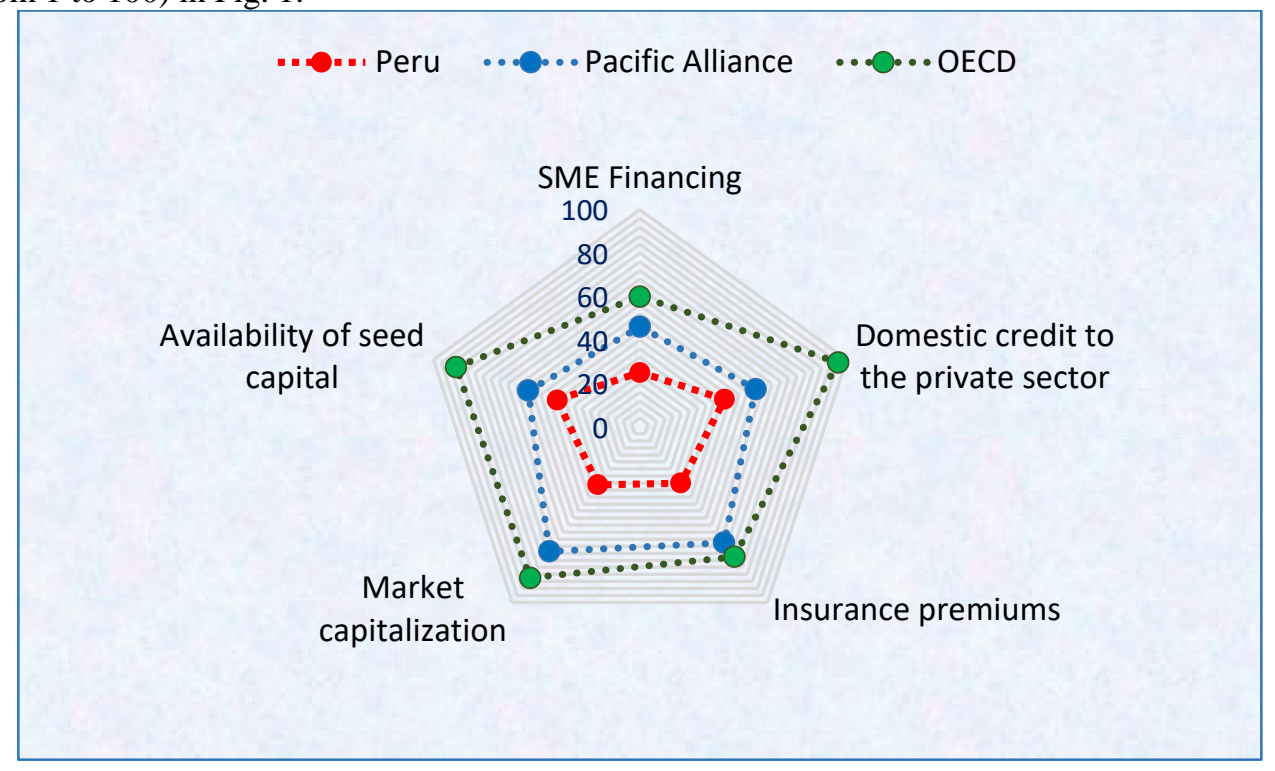

Fig. 1. Deepening the financial system

The figure shows that between 1993 and 2018, credit to the sector private (\% GDP) in Peru grew more than three times from $13 \%$ to $41 \%$, 56\% in Latin America and $96 \%$ in the OECD. However, this indicator is still low compared with the average in other countries.

Also, an additional reflection of lower levels of efficiency and competition from the Peruvian financial market, is the high interest rate spread, which in the case of Peru it amounts to $14.4 \%$, well above the average exhibited by countries Latin America $(8.7 \%)$ and the OECD $(3.3 \%)$. In this way, the low depth and efficiency of the market local financial affects the dynamics business, through lower productivity and accumulation capital, especially for firms with greater difficulties in accessing financing [3].

Added to this is the high costs of financing in Peru, especially for smaller firms such as microenterprises, which can get to pay interest rates annually on average 4-5 times more than big companies. This data could even be underestimating the effective cost of access to business credit, given the proliferation of informal activities.

However, it is necessary to mention also regulatory improvements ongoing under the Alliance of the Pacific, in order to have a more developed and integrated financial market. So, they have taken carry out regulatory changes related to crowdfunding, under standards 
such as regulatory flexibility, technological neutrality, financial stability, prevention money laundering, among others.

It also seeks to develop a ideal legal framework for the implementation of a passport of funds that allows investors to be recognized more easily residents between countries of the Pacific Alliance. Further, In the field of factoring, you are promoting the adequacy of regulation among member countries, to promote guidelines that allow the issuance of negotiable electronic invoices in the Stock market.

Finally, it is noteworthy that some ventures have chosen to develop new financing alternatives that are not yet properly regulated. So we have factoring ventures and financial technology (Fintech), the same as given its characteristics, ductility and simplicity, they are being configured as financing options mainly for companies of less size.

\section{Methodology}

Financial technology or Fintech is an emerging industry that presents an innovative take on modern financial services. Such an industry goes hand in hand with the Internet revolution; Thus, the industry and the Internet revolution have grown exponentially. Thus, Fintech companies are seen as potential online allies for traditional banking systems.

\section{Results}

The various technological developments that have occurred worldwide over the past decade -alongside the new business models they have generated-are shaking up the financial services industry's status quo. Today, it is impossible to analyze the sector without considering the impacts of the new financial technologies and the entrepreneurs and Fintech companies that are implementing them. These are the new stakeholders competing with traditional financial institutions and challenging their largely established business models. While it is still unclear whether the sector is transformation will occur through competition or cooperation between them, the changes that this technological revolution entails are irreversible. Fortunately, this dynamic of unstoppable changes constitutes a series of good news for Latin America.

First, it's worth mentioning that the financial services industry's reconfiguration following the outbreak of Fintech is likely to contribute to bridging the financial gap affecting the region's productive sector. This is especially true for small and medium enterprises (SMEs), which play a critical role in productive development, employment, and economic growth in Latin America. On the one hand, the emergence of new online financial platforms and intermediaries -with lower transactional fees and new techniques and information sources to assess credit risk- will contribute to boost SMEs access to credit. On the other hand, existing payment solutions and digital tools to obtain better business financial performance shall not only promote these transactions' digitalization and formalization, but also make the transaction history or digital footprint available to evaluate credit risks, creating new options to solving information asymmetries and positive consequences in terms of opportunities to obtain financial support. All of this can generate a virtuous cycle that contributes to solve the persistent challenge of the high levels of SME informality -which poses an obstacle to financial access- and SMEs impact on productivity levels. This potential is reaffirmed by the fact that one out of every four Fintech startups in the region focuses exclusively on serving the small and medium enterprises.

Secondly, this emerging context offers additional, better chances to serve a broad segment of the population that remains excluded or underserved by the traditional financial industry -most adults in the region. It's worth noting that while financial exclusion, as measured by 
the possession of a bank account to holding a bank account, is estimated at about $49 \%$-, this figure rises significantly when the use of credit, savings or insurance instruments is factored [13].

The greater presence, activity, and collaboration with traditional actors in the financial services industry-banks, payment agencies, insurance companies, and stock exchanges, among others - Fintech is a further indicator of the development in the region with respect to innovation in this sector. Five years ago, it was unthinkable for anyone to talk about open innovation programs that pursue tangible benefits for the digital transformation of the industry in the form of pilot, proof-of-concept testing, corporate venture capital, and immersion programs [15]. Today, this is the new normal, with local, regional, and international actors establishing a significant presence with the intention of approaching and collaborating with Fintech companies.

As seen in 2019, the Fintech start-ups in Latin America provide a range of solutions throughout different business segments. The 1,166 young Fintech businesses identified in this new edition are distributed among 11 Fintech business segments. Among them, the following three segments are the most representative of the Fintech sector in terms of number of start-ups. Together they represent 58 percent of the total number of start-ups identified: payments and remittances, with 285 Fintech startups, which constitutes 24 percent of the total; lending, with 208 Fintech start-ups, accounting for 18 percent of the total number; and enterprise financial management, with 181 Fintech start-ups, 15 percent of the total (Figure 2 and Figure 3).

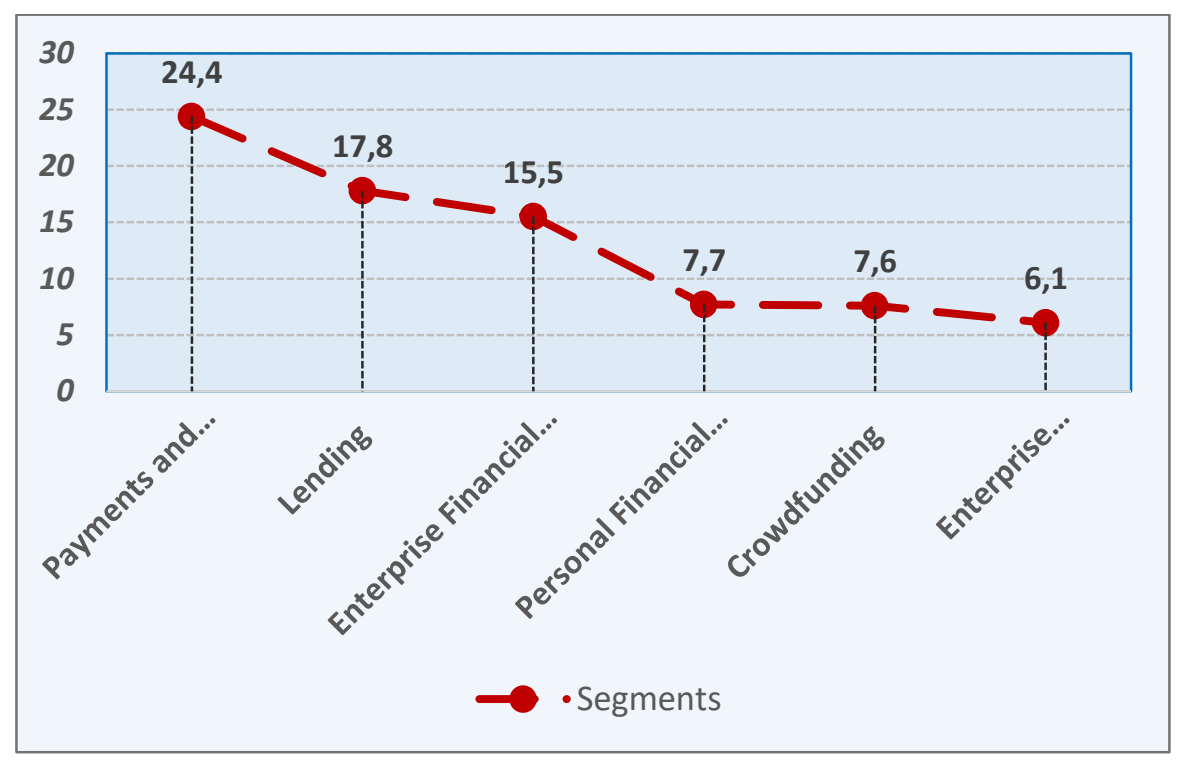

Fig. 2. Segment analysis 


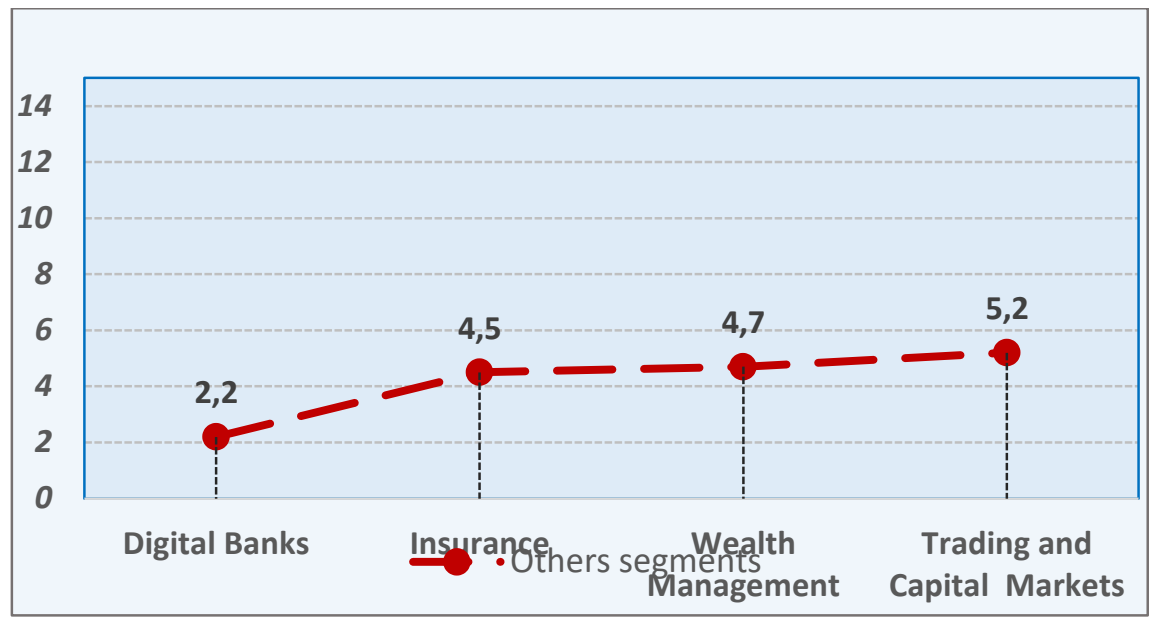

Fig.3 Analysis of other segments

As can be seen from the figures, there is a great need for business to obtain tools to improve the management of their resources and the transition to digital finance.

The size of these three segments is explained to a large extent by the massive penetration of mobile devices in the region, the large numbers of people underserved or excluded from the formal financial system, and limitations or inefficiencies in the services offered by traditional financial actors [20].

The prevalence of mobile payment solutions and money transfers is largely due to the high level of penetration of smart devices in the region, which by 2017 already reached 67 percent (GSMA, 2018) of the population, and high exclusion rates.

In addition, the limited availability of loans, which implies high access costs and interest rates when provided by traditional financial services, has created an opportunity that has led to the emergence of new models aimed at providing more efficient and less costly financing solutions for Fintech firms. Finally, the wide range of corporate finance management solutions offered is an excellent opportunity in the region, given the importance of the small and medium-sized enterprises (SMEs) sector, which represents approximately 90 percent of companies in Latin America and the Caribbean, and which faces the challenge of progressive digitalization. First of all, enterprises need to get the tools to better manage their resources and move to digital finance.

The remaining segments account for less than 10 percent of the total number of identified startups, although all of them showed growth of more than 25 percent compared to last year, which indicates the dynamics and dynamism of the ecosystem of the Fintech region. These segments include personal finance management (90 start-ups, 8 percent of the total), crowdfunding (89 start-ups, 8 percent of the total), corporate technologies for financial institutions ( 71 start-ups, 6 percent of the total), trading capital markets ( 61 startups, 5 percent of the total), money management (55 startups, 5 percent of the total), insurance (54 startups, 5 percent of the total) and digital banks (26 startups, 2 percent of the total).

When comparing the distribution among different fintech. As for the segments in relation to the results of 2017, it should be noted that the same hierarchical order is applied in almost all Fintech segments in relation to the number of startups.

Outside the sector size, when the growth percentage is reflected in each, as in 2017, in many cases the strongest growth is not observed in the segments that can currently show the largest number of startups. 
Firstly, growth rates in excess of 100 percent are experienced by one of the smallest segments in terms of the number of startups: credit scoring of digital banks with a growth rate of 160 percent, achieved by increasing from 10 to 26 startups (Figure 4).

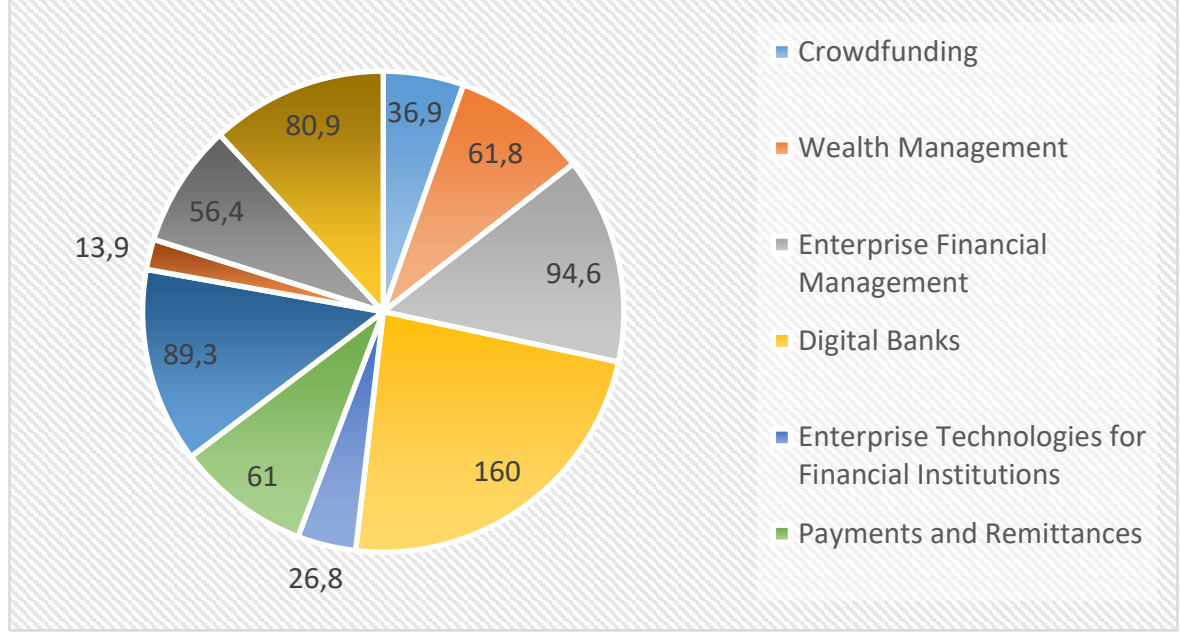

Fig. 4. Segment growth

The increase in the digital banks segment reflects the need to provide banking products and services that attract and address the needs of new generations, as well as the importance of mobile devices for conducting bank transactions.

None of the 11 Fintech segments identified has experienced a contraction since the previous edition of this report; 6 of them have grown between 50 and 100 percent in the last year, a sign of the sector's dynamism. These high-growth segments are: enterprise financial management (95 percent), insurance ( 89 percent), lending (81 percent), wealth management (62 percent), trading and capital markets (56 percent).

The personal financial management segment has experienced the lowest growth among all the Fintech segments since 2017, with a growth rate of 14 percent. However, in the region's main Fintech ecosystems (Brazil, Chile, Colombia, and Mexico), this segment has always been positioned among the five with the highest number of Fintech start-ups; lower growth, therefore, might be a reflection of market saturation. Even so, the IDB and Finnovista believe that personal financial management will become a key segment in the future, since the desegregation of supply of services provided by Fintech companies will have to be aggregated in the near future in a kind of digital financial services supermarket, and the startups in this segment are best positioned to carry out this aggregation. Moreover, personal financial management solutions play a fundamental role in educating and developing financial capacities by offering tools that enable people to manage their spending and their saving more efficiently and intuitively.

The results from this study are very positive and show that the dynamic Fintech sector is developing in Latin America, offering a wide range of solutions that include all segments and basic technologies used around the world.

Nevertheless, although the forecast looks promising, the sector still young and needs a strong ecosystem that can contribute to adequate growth. Here, the public sector can play a key role in developing strategies and policies that maximize the benefits that Fintech offers in a context that protects consumers and the financial system, while minimize risks for both.

\section{Discussions}


Alternative finance platforms. Presently, many people and businesses in the region are unable to access a loan from the traditional financial system. The reasons range from a lack of a credit history to guarantee the borrower, which creates higher transaction costs for financial intermediaries, to problems of information asymmetry, bureaucratic demands, and costs of scaling up, among others[9].

Faced with this situation, solutions have emerged in Latin America using new business models that offer alternative sources of funding for consumers and companies, including lending solutions (60 percent of the total), whether these are balance sheet or peer-to-peer; crowdfunding solutions (30 percent of the total), and factoring (10 percent) (Figure 5).

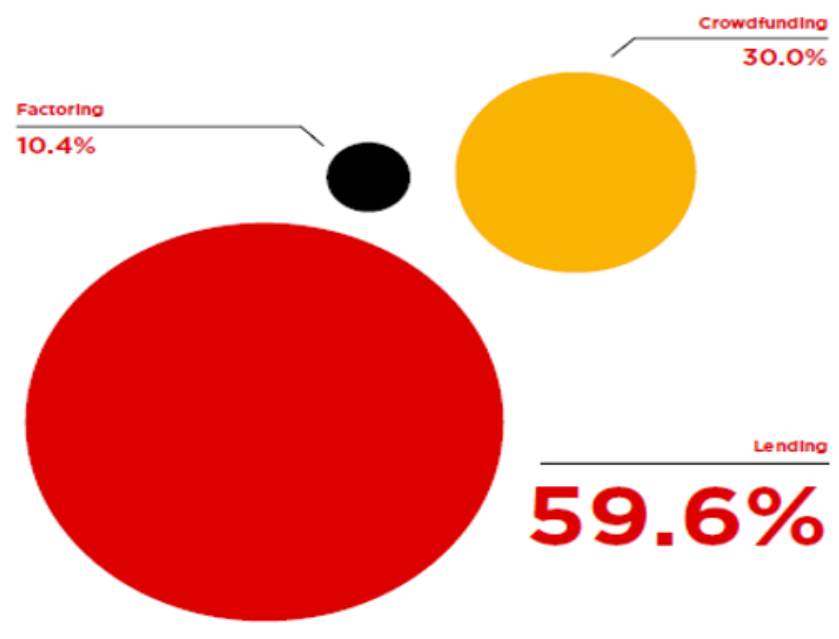

Fig. 5. Sub-segmentation: Alternative Finance Platforms

Compared with the results obtained in 2017, the sub-segment that has experienced the highest growth is factoring, which has grown by 82 percent. It is followed by lending, with a growth rate of 81 percent, and by crowdfunding solutions, which rose by 46 percent over the previous year.

Furthermore, the solutions that finance balance sheet consumer lending remain in the majority (75 percent of the total) with regard to the platforms that operate using a peer-topeer (P2P) model (25 percent of the total). Furthermore, consumers continue to be the principal target market for lending solutions, as 68 percent of them provide services to consumers, whereas 32 percent focus on businesses. Figure 6 illustrates the distribution of the 177 lending alternatives. 


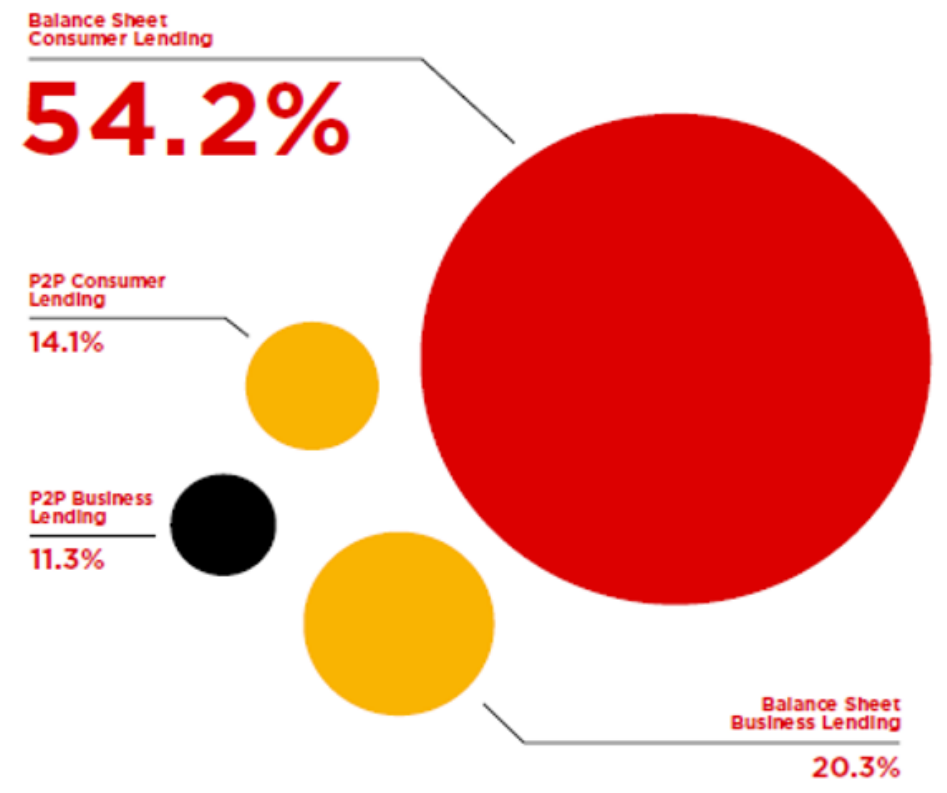

Fig. 6. Sub-segmentation: Lending

Crowdfunding emerges as an alternative finance option in which investors finance projects in exchange for a share of the business or rewards, or they simply make an investment as a donation. In Latin America a higher number of crowdfunding solutions use the latter donation model ( 32 percent of the total). This is indicative of the surge in the sharing economy, as well as in entrepreneurial culture, which generates more interest in supporting and participating in different kinds of projects. It is followed by the real estate crowdfunding sub-segment ( 27 percent of the total), through which anyone can invest small amounts of money in real estate developments and obtain interest, an activity previously limited to investors with large sums of money. In Mexico, this sub-segment grew by 730 percent over last year. Mexico recently announced that a specific regulation for this sub-segment might be included in the general framework of the Fintech Law approved in March 2018 Figure 7 shows the distribution of the 89 crowdfunding solutions. 


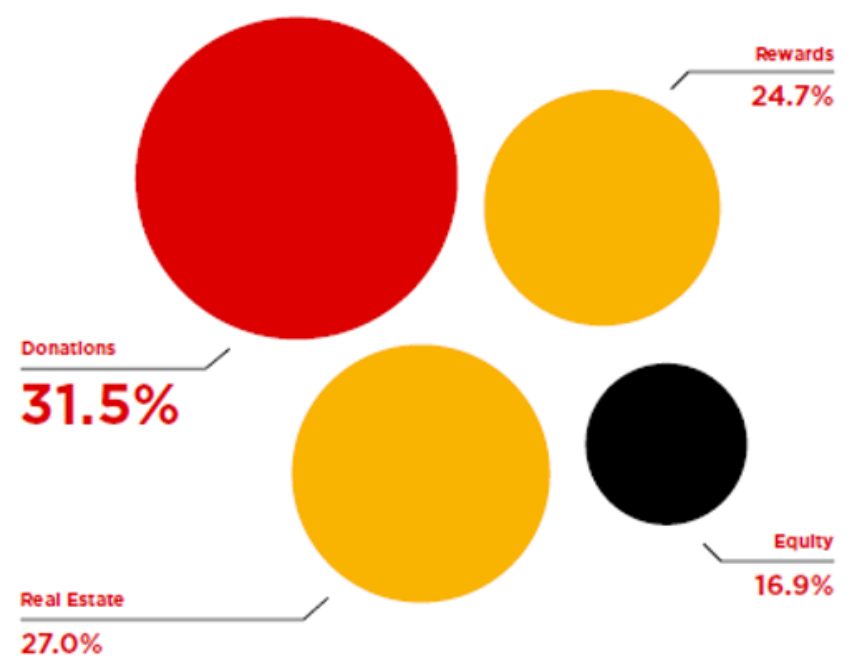

Fig. 7. Sub-segmentation: Crowdfunding

SMEs are a crucial segment of the economy in Latin America. They are increasingly more likely to digitize their businesses to achieve more efficient and optimal management. In this scenario, the enterprise management solutions that help reduce costs and

the time devoted to administrative tasks thanks to technology have increased to a large degree. Within this segment, there are more financial management and business intelligence solutions (40 percent of the total), followed by digital accounting (20 percent), electronic invoicing (20 percent), and payment collection (16 percent) (Figure 8).

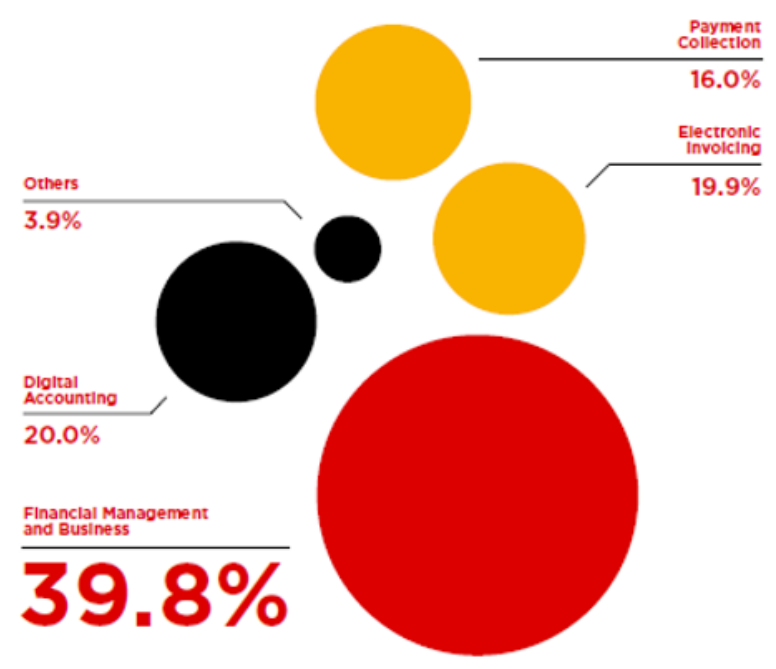

Fig.8. Sub-segmentation: Enterprise Financial Management

If the growth data for each sub-segment are compared to the previous year, the financial management and business intelligence sub-segment and the electronic invoicing segment 
grew by 125 percent. This increase reflects the need for businesses to digitize their accounting and administrative processes to gain greater control of the firms' financial situation, as well as to adapt to new regulations in countries that impose electronic invoicing, such as Argentina and Chile.

Access to financial resources continues to be a critical issue in the LAC region with regard to poverty reduction and more inclusive economic growth. Currently, more than 50 percent of the region's population is excluded from the formal banking sector. Of the 2 billion people in the world who do not have a bank account, 210 million live in the LAC region. According to a Findex study (World Bank, 2017), in 2017, only 54 percent of the region's adults had access to a bank account, compared to 39 percent in 2011. In 2017, only 12 percent of the population had savings in an official financial institution, 9 percent took a loan from a financial institution, and it is estimated that 61 percent of the region's population pays their bills in cash.

Beyond payments and transfers through mobile devices, Fintech firms offer a wider range of products aimed at improving access to financial products, especially for SMEs. An example of this is access to new models for raising credit or capital, which creates a new business funding scenario[18].

Currently, it is almost impossible for many SMEs to obtain a loan, due either to their inability to pass a credit history check (or its high costs), or because they lack the necessary collateral. Fintech companies have developed alternative scoring systems by developing algorithms that can analyze credit risk innovatively and thereby make decisions about a customer's solvency [6]. This broadens SMEs' access to bank loans when they have little or no credit history.

Furthermore, the region's banking systems reveal that the major banks in each country enjoy a high market share and set high annual interest rates. Fintech firms provide alternative finance options that offer lower interest rates and easier and more intuitive user experiences. According to Goldman Sachs estimates, the US $\$ 177$ billion provided in loans to small companies by the traditional banking system are at risk of being affected by such bank disintermediation [5].

Some examples of such Fintech companies are Konfio, an online lending platform for small companies in Mexico that uses alternative credit ratings to provide faster loans and thereby enables companies to develop their business, and TiendaPago, which offers microcredit for short-term capital to small local businesses through agreements with large distributors to finance and insure the inventory of products that are key to their business. For more information and details about this trend in Fintech alternative finance for businesses and SMEs in Latin America, as well as the study that analyzes the cases of Mexico and Chile in more depth, see the publications by the Cambridge Centre for Alternative Finance (2017 and 2018), which were elaborated with IDB support.

\section{Conclusion}

The article analyzes the characteristics, trends and the growing dynamics of the Fintech industry in Latin America. It is clear that the digitization of the financial sector is inevitable opens the door for entrepreneurs to accelerate innovation and change the way people interact with their financial services, until recently. Fortunately, entrepreneurs all over Latin America are responding to these opportunities, offering new services and innovative business models for everyone segments, and taking a concrete approach for an adequate solution various customer segments to develop appropriate value offers. The importance of this becomes clearer Keep in mind that these young businesses are better adapted to current changes in demographics or user behavior at the same time meets expectations that the system is traditional the actors have yet to tackle. 


\section{References}

1. Y. Barykina, IOP Conference Series: Materials Science and Engineering, 667(1), 012012 (2019)

2. N. Delcoure, International Review of Economics and Finance, 16(3), 400 (2007)

3. Y. Barykina, IOP Conference Series: Materials Science and Engineering, 667(1), 012011 (2019)

4. H. Edison, F. Warnock, Journal of Empirical Finance, 10(1-2), 83 (2003)

5. N.V. Kretova, G.I. Khokhlova, A.A. Kretova, Yu. Khokhlova, Conference Series: Materials Science and Engineering, 880(1), 012096 (2020)

6. E.F. Fama, K.R. French, Journal of Financial Economics, 76 (3), 549 (2005)

7. G. Khokhlova, N. Kretova, V. Sergeev, MATEC Web of Conferences, 212, 08019 (2018).

8. M. Fratzscher, M. Bussière, European Central Bank working paper, 348 (2004).

9. A.S. Nechaev, D.A. Antipin, O.V. Antipina, Journal of Mathematics and Statistics, 10(4), . 443 (2010)

10. W. Goetzmann, P. Jorion, P. Journal of Financial and Quantitative Analysis, 34(1),1 (1999)

11. A. Nechaev, O. Antipina, Economic Annals-XXI, 1-2(1), 73 (2014)

12. T. Gwatidzo, K. Ojah, African Finance Journal, 11(1), 1 (2009)

13. A.S. Nechaev, O.V. Antipina, Journal of Advanced Research in Law and Economics, 7(3), 561 (2016)

14. G. Huang, G, F.M. Song, F.M. China Economic Review. 17(1),14 (2006)

15. A. Nechaev, A. Rasputina, IOP Conference Series: Earth and Environmental Science, 421(3), 032010 (2020)

16. O. Hübler, L. Menkhoff, C. Suwanaporn, The World Economy, 31(3), 393 (2008)

17. A.S. Nechaev, S.V. Zakharov, Y.N. Barykina, M.V. Vel'm, O.N. Kuznetsova, Journal of Sustainable Finance and Investment, 2, (2020).

18. M. Tyapkina, Y. Mongush, E. Ilina, IOP Conference Series: Materials Science and Engineering, 667(1), 012105 (2019)

19. S.V. Zakharov, Actual Problems of Economics, 166(4), 198 (2014)

20. S.V. Zakharov, A.S. Bovkun K.O. Vasiliev K O International Conference IT and QM and IS, 32, 8085754 (2017)

21. S.V. Zakharov, A.O. Troshina, A.U. Lobova, International Conference IT and QM and IS,. 601, 8085895 (2017)

22. S. Zakharov, S. IOP Conference, 667(1) 012108 (2019) 